\title{
Early diagnosis of acute laryngeal injuries
}

\author{
Thomas A. Weimert \\ Department of Otorhinolaryngology, University of Michigan Medical Center, Ann Arbor, \\ Michigan
}

\begin{abstract}
Summary
Most acute laryngeal injuries are caused by motor vehicle accidents. Patients with multiple injuries who present with head or chest wounds should be carefully examined for signs or symptoms of laryngeal trauma. Primary patients with laryngeal injury presenting with life-threatening airway obstruction present a special problem to the accident surgeon. Tracheostomy rather than intubation is then the procedure of choice. A high index of suspicion must be maintained if laryngeal trauma is to be recognized and treated early. Prompt diagnosis and appropriate management is essential in maintaining an airway, preventing subsequent laryngeal stenosis and preserving the quality of the voice.
\end{abstract}

\section{INTRODUCTION}

IN the past, the lack of interest in the subject of acute laryngeal injuries undoubtedly stemmed from the fact that most of them did not become chronic, and that the patients recovered completely with only minor complications (Nahum, 1969). With the increased speed of travel, laryngeal injuries which now occur are, if not fatal, usually far more extensive than previously. The success of repair of chronic laryngeal stenosis is disappointing and inconsistent. As a result, the importance of adequately diagnosing and treating the acute injury has become more apparent. Those cases of acute laryngeal damage which do become chronic have resulted primarily from delays in treatment because they are not suspected nor diagnosed. Early diagnosis and appropriate treatment will often prevent critical obstruction of the airway and play a large part in determining the subsequent quality of the patient's voice. The accident surgeon has a key role to play at this stage.

\section{MECHANISM OF INJURY}

In comparison with the total number of injuries to the head and neck, the number involving the larynx is small (Fitz-Hugh et al., 1962). This is because of the anatomy of the larynx and its location (LeMay, 1971). The larynx is an exposed structure but is protected against external violence (Pennington, 1964) because $a$, it is suspended by ligaments and muscles and is therefore mobile and can elude a crushing blow; $b$, the mandible protects the thyroid cartilage and $c$, the spine protects the larynx posteriorly (but unfortunately may act as an anvil to anterior direct blows). When struck, the flexibility and resilience of the cartilage and soft tissue dampen the intensity of the force, thus reducing the actual severity of the trauma (Maran and Stell, 1970). The elasticity of the tissues thus has a marked influence on the extent and nature of the injuries. This is probably one reason that laryngeal damage is uncommon in the compliant larynx of the child (Fitz-Hugh and Powell, 1970; Kotarba, 1973).

The majority of injuries are caused by blunt forces which produce injuries of a hidden character. In contrast, the damage caused in penetrating wounds is usually easy to ascertain because of the location of the entrance wound (Jones et al., 1967; LeMay, 1971). The most characteristic injury associated with blunt laryngeal trauma is fracture of a facial bone (Ogura and Powers, 1974).

Nlmost all patients seen and treated for blunt trauma of the larynx are involved in motor vehicle collisions. A lesser number result from other blunt trauma such as fist fights and sports 
accidents. Most neck injuries in automobiles occur when the car is struck from behind, when the occupant's neck is forced into sudden hyperextension, but the larynx is not injured by this type of accident. It is in head-on collisions that the larynx sustains injury. The head and mandible are thrown back, and the neck is extended, fixing and exposing the larynx. The vulnerable laryngeal structures are then thrust against the dashboard, steering wheel or front scat, compressing the structures against the cervical vertebrae. The sites and frequency of laryngeal injury in Pennington's (1964) study arc shown in Table $I$.

Table I. Site and frequency of laryngeal injury in 22 patients who were treated by open repair

\begin{tabular}{|c|c|}
\hline Site of injury & $\%$ \\
\hline $\begin{array}{l}\text { Vertical midline fracture of } \\
\text { thyroid cartilage }\end{array}$ & 81 \\
\hline $\begin{array}{l}\text { Posterior displacement of base } \\
\text { of epiglottis and rupture } \\
\text { of thyro-epiglottic ligament }\end{array}$ & 50 \\
\hline $\begin{array}{l}\text { Severe tears and abrasions of } \\
\text { mucosal surfaces of } \\
\text { ventricular folds and true cords }\end{array}$ & 45 \\
\hline $\begin{array}{l}\text { Separation of vocal ligaments } \\
\text { and thyro-arytenoid muscular } \\
\text { attachments }\end{array}$ & 27 \\
\hline $\begin{array}{l}\text { Laryngotracheal separation and } \\
\text { recurrent laryngeal nerve damage } \\
\text { Pyriform sinus and cervical }\end{array}$ & 18 \\
\hline $\begin{array}{l}\text { oesophageal tears } \\
\text { Gross arytenoid disruption }\end{array}$ & $\begin{array}{r}13 \\
9\end{array}$ \\
\hline
\end{tabular}

\section{SIGNS AND SYMPTOMS}

All degrees of laryngeal injury may occur. It is of foremost importance to determine which patients have sustained a bad cnough injury to require admission to hospital or special treatment. Assessing the severity of a laryngeal injury can be challenging and frustrating. Blunt laryngeal damage, in fact, often goes undiagnosed in the early critical stages. Diagnosis is particularly difficult in the semi-comatose patient, who frequently has more obvious reasons for airway distress.

The diagnosis may often be established on the history and physical examination. Laryngeal injury should be suspected in the presence of the following signs (Nahum, 1969).
1. Cervical subcutaneous emphysema. This may be detected by palpation or by radiography.

2. Voice impairment. An abnormal voice may be due to cerebral damage but the larynx must be examined before any voice change can be attributed to a head injury. From the onset of the injury, the voice may be hoarse. Changes of voice quality, however, should not be taken as a guide to the severity of the injury. It has not been useful clinically for ultimate evaluation of airway patency.

3. Increasing airway obstruction. Stridor, noisy inspiration, dyspnoea, sternal retraction and acute or chronic hypoxia also demand examination of the upper airway.

4. Haemoptysis.

5. Cough.

6. Dysphagia or pain on swallowing.

7. Palpable evidence of fracture-dislocation. This is indicated by loss of the thyroid notch or loss of thyroid or cricoid prominence.

8. Damage to the soft tissue of the front of the neck. The appearance of the neck may, however, be quite misleading as far as the degree of injury is concerned. Various types of laryngeal injuries may occur with little evidence of damage to the tissues overlying the airway, thus making the diagnosis or extent of injury difficult to evaluate (Chadwick, 1960; Miles et al., 1971; Ogura and Powers, 1974).

9. Pneumothorax or pneumomediastinum. 10. Atelectasis.

The causes of the early signs and symptoms of acute laryngotracheal injuries are shown in Table II (Fitz-Hugh and Powell, 1970).

\section{RADIOLOGY}

Soft tissue radiographs of the neck help to demonstrate the presence of air in tissues and areas of localized swelling. They may show the presence or absence of fracture of the hyoid bone. Posterior displacement of the epiglottis as well as other distortions of the air column may also be scen. Unfortunately, conventional vicws obtained early in the case of acute injury do not show cartilaginous structures well.

Tomograms and laminograms are sometimes helpful, although the condition of the patient frequently does not permit these special views. They are more valuable in the evaluation of late sequelae.

Contrast media are occasionally used to demonstrate intralaryngeal and pharyngeal trauma, but not routinely in acute cases. The swelling of soft tissues makes accurate interpretation difficult. 
Table /I. Symptoms and signs of laryngotracheal injuries

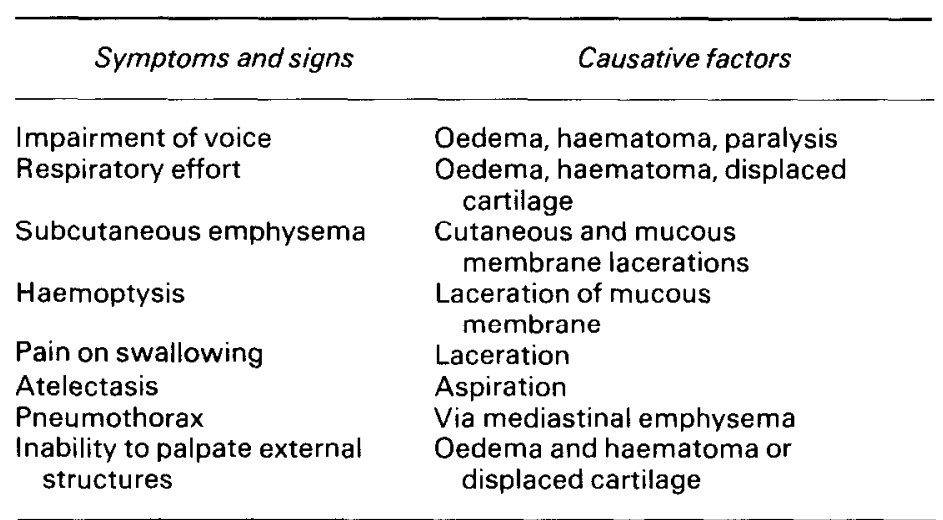

\section{ENDOSCOPY}

The mainstay in the diagnosis of acute laryngeal trauma is indirect laryngoscopy (Nahum, 1969). This is often possible in the cooperative, conscious patient with a controlled airway. Indirect inspection can be obtained of glottic motion, mucosal tears, haematoma, dislocation and distortion of the lumen. Too great an effort to accomplish a mirror examination, however, may jeopardize the airway. Prompt evaluation is desirable, but good judgement must be used.

\section{TREATMENT}

If a patient with a laryngeal injury has other injuries, these should be given the necessary priority. Associated injuries of the head and neck must always be considered. Laceration of the cervical oesophagus is not rare and proper diagnostic measures should be carried out (May et al., 1976). Fracture-dislocation of the cervical spine not uncommonly occurs in patients with laryngeal damage. This must be investigated with appropriate radiographs before manipulation of the head and neck is carried out. While evaluating these injuries, however, the possibility of blunt laryngeal damage must not be overlooked.

The most urgent decision which must be made in the management of these patients involves the establishment of an adequate airway. Intralaryngeal haematoma and oedema are already extensive within the first hour after injury (Chadwick, 1960; Fitz-Ilugh et al., 1962; Miles et al., 1971). Unless additional bleeding occurs, oedema is maximal within six hours (Miles et al., 1971). In the absence of progressive sub- cutancous emphysema, further obstruction of the airway is not then likely.

The patient should not be intubated if severe laryngeal trauma is suspected (Nahum, 1969). If it is obvious that the airway patency must be restored for survival, tracheotomy is indicated. Many emergency rooms have anaesthetists who help to deal with urgent airway difficulties. They often intubate primarily. When there is reasonable evidence of laryngeal injury, intubation is contraindicated. Endoscopy may then result in further anatomical distortion, mechanically aggravating the injury.

In those patients who have a lesser degree of airway obstruction, humidification, elevation of the head and an intravenous injection of steroid will help to prevent subsequent oedema and further airway obstruction.

\section{REFERENCES}

Chadwick D. I. (1960) Closed injuries of the larynx and pharynx. J. Laryngol. Otol. 74, 306.

Fitz-Hugh G. S. and Powell J. B. II (1970) Acute traumatic injuries of the oropharynx, laryngopharynx and cervical trachea in children. Otolaryngol. Clin. North Am. 3, 375.

Fitz-Hugh G. S., Wallenborn W. M. and McGovern $\Gamma$. (1962) Injuries of the larynx and ccrvical trauma. Ann. Otol. Rhinol. Laryngol. $71,419$.

Jones R. F., Terrell J. C. and Salyer K. E. (1967) Penetrating wounds of the neck: an analysis of 274 cases. J. Trauma 7, 228.

Kotarba E. (1973) External injuries to the larynx. $J$. Laryngol. Otol. 87, 69 .

LeMay S. R. (197I) Penetrating wounds of the larynx and cervical trachea. Arch. Otolaryngol. 94, 558.

Maran A. G. D. and Stell P. M. (1970) Acute laryngeal trauma. Lancet 1, 1107. 
May M., Tucker H. and Dillard B. (1976) Penetrating wounds of the neck in civilians. Otolaryngol. Clin. North Am. 9, 361 .

Miles W. K., Olson N. R. and Rodriguez A. (1971) Acute treatment of experimental laryngeal fractures. Ann. Otol. Rhinol. Laryngol. 80, 710.

Nahum A. M. (1969) Immediate care of acute blunt laryngeal trauma. J. Trauma $9,112$.
Ogura N. R. and Powers W. L. (1974) Functional restitution of traumatic stenosis of the larynx and pharynx. Laryngoscope 74, 1081.

Pennington C. L. (jun.) (1964) Glottic and supraglottic laryngeal injury and stenosis from external trauma. Laryngoscope 74, 317 .

Requests for reprints should be addressed to: Dr Thomas A. Weimert, Department of Otorhinolaryngology, St Joseph Mercy Hospital, PO Box 994, Ann Arbor, MI 48108, USA.

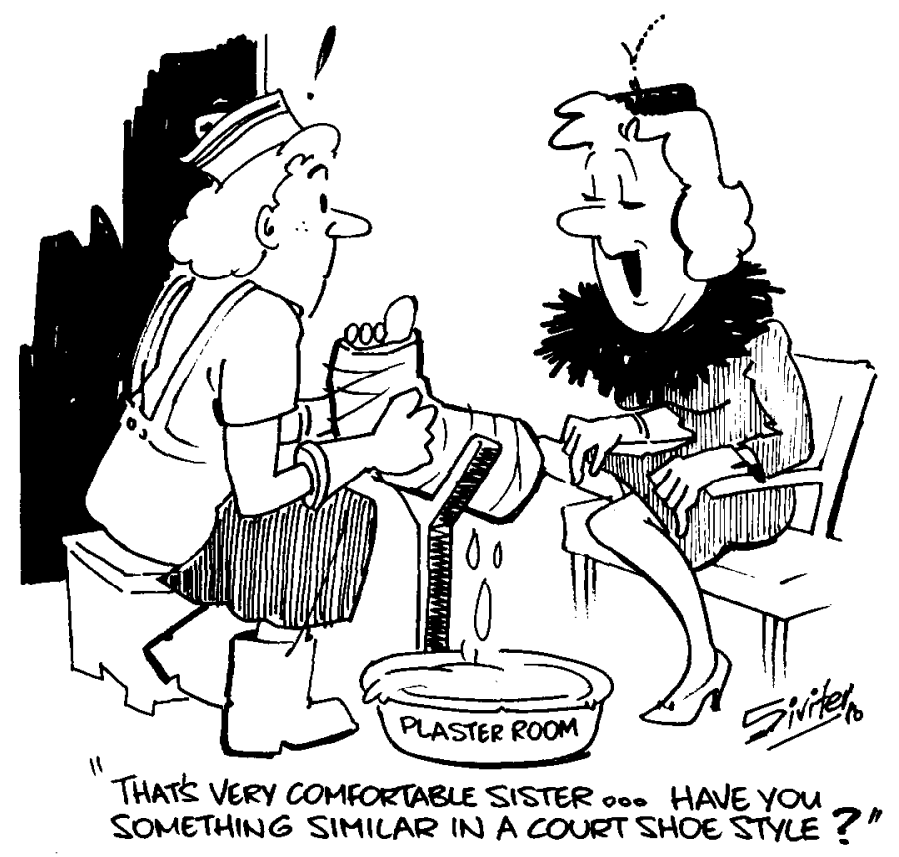

